\title{
Overdose of oral contraceptive pills as a means of intentional self-poisoning amongst young women in Sri Lanka: considerations for family planning
}

\author{
Manjula Weerasinghe, ${ }^{1}$ Flemming Konradsen, ${ }^{2}$ Michael Eddleston, ${ }^{3}$ \\ Melissa Pearson, ${ }^{4}$ Thilini Agampodi, ${ }^{5}$ Frederikke Storm, ${ }^{6}$ \\ Suneth Agampodi ${ }^{7}$
}

For numbered affiliations see end of article.

\section{Correspondence to Mr Manjula Weerasinghe, Department of Community Medicine, Faculty of Medicine and Allied Sciences, Rajarata University of Sri Lanka, Saliyapura, Anuradhapura 50008, Sri Lanka; manjugaya@yahoo.com}

Received 6 January 2015 Revised 2 February 2016 Accepted 25 February 2016 Published Online First 22 March 2016

CrossMark

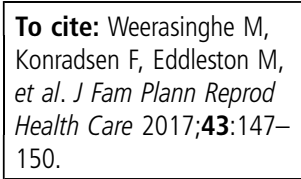
Konradsen F, Eddleston M, et al. J Fam Plann Reprod Health Care 2017;43:147150.

\begin{abstract}
Objective Oral contraceptive pills (OCPs) are one of the most popular family planning methods in Sri Lanka. As part of two hospital-based studies on self-harm, the use of OCPs was identified, from yet unpublished results, as a means of intentional self-poisoning. To inform future guidelines for better OCP promotion, this article aims to describe the extent, patient characteristics and outcomes of OCP self-poisoning in the North Central Province of Sri Lanka.
\end{abstract}

Methods A secondary analysis was carried out on two hospital-based self-harm case series, from January 2011 to June 2014.

Results Fifty-four patients (52 women and two men) with an overdose of OCP as a means of intentional self-poisoning were admitted to one of the surveyed hospitals. The median age of the patients was 19 (interquartile range, 5) years. None of the patients were severely sick from their overdose and two-thirds of the patients were discharged within a day of admission. Intentional self-poisoning with OCPs represented less than $5 \%$ of all types of intentional medicine self-poisonings recorded at the hospitals. Information available for a subset of female patients indicates that many cases (13/23, $56.5 \%)$ were in their first year of marriage. Conclusions More research is required to understand why young women in rural Sri Lanka overdose with OCPs as a means of intentional self-poisoning. Although the toxicity of OCPs is low and the public health significance of OCP poisoning remains minor, reproductive health service providers should be attentive to OCP overdose, monitor the development of this problem, and ensure appropriate information to OCP users.

\section{Key message points}

- This is the first published article describing the deliberate ingestion of oral contraceptive pills (OCPs) as a means of self-poisoning.

- Most of the patients who took OCPs for intentional self-poisoning were young women aged between 15 and 20 years within their first year of marriage.

\section{INTRODUCTION}

In rural Sri Lanka, intentional self-poisoning is among the top ten causes of hospital deaths ${ }^{1}$ and is a major public health problem with an estimated annual 315-447 per 100000 cases of intentional self-poisoning. ${ }^{2}$ Agricultural pesticides are the most commonly used agent for intentional self-poisoning. However, cases of intentional medicinal drug self-poisoning have dramatically increased in recent years. ${ }^{4}$ Intentional self-poisoning with newer agents is a continually evolving problem and introduces new challenges, particularly if there is a lack of prior human data on clinical features, biochemical abnormalities and case fatality or if existing data are not effectively communicated to clinicians or regulators. ${ }^{5}$

Since the introduction of oral contraceptive pills (OCPs) in Sri Lanka in the early 1960 s as part of the Family 
Planning Program, their quality has gradually improved in terms of contraceptive efficacy and reduced side effects, hence availability, access and use has increased. ${ }^{6}$ As a safe and effective family planning method, public health midwives in Sri Lanka are trained in prescribing and distributing OCPs free of charge on the basis of medical history. ${ }^{7}$ In addition, OCPs are available in government and estate family planning clinics, family planning clinics conducted by non-governmental organisations, private medical centres and franchised pharmacies. ${ }^{7}$ The promotion of OCPs has made them easily available in households, over the counter at pharmacies, and they are one of the most popular contraceptive methods.

The aim of this article is to describe the extent, patient characteristics and outcomes of OCP intentional self-poisoning in the North Central Province of Sri Lanka. Such information can be used to inform OCP promotional efforts, clinicians and public health authorities.

\section{METHODS}

We carried out a secondary analysis of two hospitalbased case series from two different studies in the North Central Province (NCP) of Sri Lanka. The province has a population of 1.2 million (2011 census data) with most livelihoods based on agriculture. The first case series was a cross-sectional survey of selfharm cases (unpublished data) from 48 primary hospitals located within the NCP for the period 1 January to 31 December 2011. The second case series was harvested from a surveillance study of self-harm cases registered at primary $(n=10)$ and referral $(n=2)$ hospitals located mainly within the Mahaweli $\mathrm{H}$ region of the NCP for the period January 2012 to June $2014 .^{8}$ In both studies, wards covered for data collection included medical wards (male and female) and paediatric wards (age $\leq 12$ years).

A separate sub-study was carried out as part of the second case series, focusing on the collection of additional information from medical records (termed Bed Head Tickets), including pregnancy status, marital status, number of ingested OCP tablets and whether the patients self-poisoned with other medicines in addition to OCPs.

An OCP intentional self-poisoning patient was defined as a patient, admitted to a medical or paediatric ward at a primary or referral hospital in the NCP during the study period with an overdose of OCPs following self-poisoning.

Data for the first case series were collected from the government hospitals on behalf of the Provincial Director of Health Services for clinical audit and service evaluation purposes. In agreement with the permission granted by the Provincial Directorate, no patient names and addresses were recorded for this study. Likewise, no patients were interviewed and no specimens collected. Ethics approval for the second case series were granted by the ethical review committees at the University of Peradeniya, Sri Lanka and Rajarata University of Sri Lanka.

\section{RESULTS}

The data identified a total of 70 admitted patients following intentional self-poisoning with OCPs from 22 hospitals. Fourteen patients were recorded in both primary and referral hospital and these duplicates were removed. Two patients, aged 6 and 2 years, were excluded from the analysis since it was assessed that they were admitted to paediatric wards following accidental OCP poisoning. The remaining 54 patients were considered for the analysis.

The 54 OCP self-poisoning patients made up 4.2\% (54/1285) of all the medicine self-poisoning patients admitted to the surveyed hospitals and accounted for only $0.7 \%(54 / 7284)$ of all self-harm patients admitted to the surveyed hospitals over the study period. Forty-nine of the 54 OCP self-poisoning patients were resident in NCP, while five patients were residing outside of the NCP but admitted to an NCP hospital following an overdose of OCP. Most $96.3 \%$ (52/54) of the OCP intentional self-poisoning patients were women. More than half of the patients $(59.2 \%, 32 / 54)$ were in the $15-$ 20 -year age group, while $24.1 \%(13 / 54)$ were aged $21-$ 25 years and $16.7 \%(9 / 54)$ were aged $>26$ years. The median age was 19 (interquartile range, 5) years. Forty patients $(74.1 \%, 40 / 54)$ were managed at the primary hospitals while $14(25.9 \%, 14 / 54)$ were transferred from a primary hospital to a referral hospital for further treatment. No direct admissions to the referral hospitals occurred. None of the patients became severely ill and two-thirds were discharged within a day of admission.

More detailed background information was available for the 25 patients identified in a sub-study as part of the second case series. Of the 25 patients, 23 were women who reported use of OCP on a regular basis for family planning purposes. Thirteen $(56.5 \%, 13 / 23)$ patients were married young women whose intentional self-poisoning act occurred within the first 12 months of marriage. None of the female patients were pregnant at the time of self-poisoning. Around one-fifth of patients had ingested other drugs in addition to OCPs. Seventeen of the $25(68.0 \%)$ patients had ingested more than 10 OCP tablets and five $(20.0 \%)$ patients had taken more than 28 tablets. The most common symptoms of patients who overdosed with OCP were severe headache, nausea and vomiting.

\section{DISCUSSION}

We have observed in our case series a small number of primarily young female patients admitted to hospitals in rural Sri Lanka following self-poisoning with OCPs. Most of the patients were teenagers or in their early twenties. Many had self-poisoned within the first year of marriage. Why young women in rural Sri Lanka overdose with OCPs as a means of self-poisoning remains to 
be explored. This could be viewed in the light of Sri Lanka's wider self-harm practices where young women are particularly vulnerable. ${ }^{9}$ In addition, the epidemiological pattern of intentional self-poisoning seems to be shifting from pesticides to medicinal drugs such as paracetamol, especially in urban areas. ${ }^{3} 410$ A study from Colombo found that this trend of using medicinal drugs was mainly among women aged $15-24$ years, ${ }^{11}$ which matches our findings on overdose of OCPs as a means of self-poisonings. Since OCPs are promoted to newly wedded couples as a recommended method to delay the first child, ${ }^{7}$ this is likely to increase availability of OCPs in such households and may explain the observed number of cases among the group of newly marrieds.

The OCP user guidelines recommend keeping an extra pack of pills in reserve. ${ }^{7}$ Our cases of patients ingesting more than 28 OCPs (i.e. one pack) indicate that having extra OCPs to hand may present a risk of misuse. Further studies are needed to assess if users fully understand the information provided about correct use of OCPs and if a change in promotion might be required.

Possible symptoms of OCP overdose include breast tenderness, discolouration of urine, drowsiness, excessive vaginal bleeding (2-7 days following the overdose), headache, emotional changes, nausea, vomiting and rash, which may be characterised as minor clinical symptoms. ${ }^{12}$ In this study, severe headache, nausea and vomiting were observed as the most common symptoms even among patients with substantial OCP overdose of more than $300 \mu \mathrm{g}$ ethinylestradiol and $1.5 \mathrm{mg}$ levonorgestrel ingested. However, we are unaware of what effect the overdose of OCPs might have on future health outcomes.

In conclusion, the toxic impact of an overdose of OCP is low, and OCPs offer women and families a good way of planning their families. Nevertheless, we need to understand whether there are knowledge gaps among OCP users in Sri Lanka about usage and storage of OCPs or whether there are other explanations for OCP misuse. This requires future studies on OCP user perceptions and practices as well as the intention behind OCP self-poisoning to inform and potentially adjust promotional activities. For example, the information to users about the correct response to missed pills as well as package size of OCPs are possible areas of interest for future studies. It may also be relevant to investigate whether similar intentional self-poisoning trends exist in other countries. Identification of new self-poisoning agents is important to allow enough time to develop guidance for clinicians and regulators.

\section{Limitations}

This article presents findings based on secondary analysis of available data; however, investigation of risk factors was not possible as part of the study design. Early pregnancies may not have been confirmed by the time of overdose, which is clearly a limitation to the interpretation of the pregnancy status of our cases. Also, it is possible that the women either did not want to disclose their pregnancy status to medical staff or their pregnancy status was missed in the medical records. It is possible that the actual numbers of intentional OCP self-poisoning cases were underestimated, especially in the first case series where referral hospitals were not included in the data collection. Finally, our findings are limited to one province and may not be generalisable to the whole of Sri Lanka.

\section{Author affiliations}

${ }^{1} \mathrm{PhD}$ Fellow and Research Co-ordinator, Department of Community Medicine, Faculty of Medicine and Allied Sciences, Rajarata University of Sri Lanka, Saliyapura, Anuradhapura, Sri Lanka and South Asian Clinical Toxicology Research Collaboration (SACTRC), Faculty of Medicine, University of Peradeniya, Peradeniya, Sri Lanka

${ }^{2}$ Professor, Head of section, Department of Public Health, University of Copenhagen, Copenhagen, Denmark

${ }^{3}$ Professor of Clinical Toxicology and Lister Prize Fellow and Director of the National Poison Information Service South Asian Clinical Toxicology Research Collaboration (SACTRC), Pharmacology, Toxicology and Therapeutics, University of Edinburgh, UK, South Asian Clinical Toxicology Research Collaboration (SACTRC), Faculty of Medicine, University of Peradeniya, Peradeniya, Sri Lanka and Department of Public Health, University of Copenhagen, Copenhagen, Denmark

${ }^{4}$ Dr, Trial Manager, South Asian Clinical Toxicology

Research Collaboration (SACTRC), Faculty of

Medicine, University of Peradeniya, Peradeniya, Sri

Lanka and Department of Pharmacology, Toxicology

and Therapeutics, University of Edinburgh,

Edinburgh, UK

${ }^{5}$ Dr, Senior Lecturer, Head of the Department, Department of Community Medicine, Faculty of Medicine and Allied Sciences, Rajarata University of Sri Lanka, Saliyapura, Anuradhapura, Sri Lanka ${ }^{6}$ Research Assistant, Department of Public Health, University of Copenhagen, Copenhagen, Denmark ${ }^{7}$ Professor in Community Medicine, Department of Community Medicine, Faculty of Medicine and Allied Sciences, Rajarata University of Sri Lanka, Saliyapura, Anuradhapura, Sri Lanka

Acknowledgements The authors would like to thank Ranjith Thilakasiri, Chaminda Prasad, Udana Senevirathna, Janaka Madawala, Shashikala Asalaarachchi, Prasanna Thilakarathna, Kalpani Dissanayaka, Tharidu Sandaruwan, Malith Eranda, Iresha Palugaswewa and Sandamali Rajapaksha from the South Asian Clinical Toxicology Research Collaboration for assistance with data collection.

Funding The authors acknowledge funding for this cross-sectional study and Safe Storage Study from the Wellcome 
Trust (GR090958), the University of Edinburgh and the University of Copenhagen.

Competing interests None declared.

Ethics approval For the second case series: by the ethical review committees at the University of Peradeniya, Sri Lanka and Rajarata University of Sri Lanka.

Provenance and peer review Not commissioned; externally peer reviewed.

\section{REFERENCES}

1 Leading causes for the deaths in a hospital. Department of Health North Central Province of Sri Lanka. http://www. healthdept.nc.gov.lk/index.php?option $=$ com_content $\&$ view $=$ article $\& i d=104 \&$ Itemid $=79 \&$ lang $=$ en $($ accessed 2 Jan 2015).

2 Manuel C, Gunnell DJ, van der Hoek W, et al. Self-poisoning in rural Sri Lanka: small-area variations in incidence. $B M C$ Public Health 2008;8:26.

3 Senarathna L, Jayamanna SF, Kelly PJ, et al. Changing epidemiologic patterns of deliberate self poisoning in a rural district of Sri Lanka. BMC Public Health 2012;12:593.

4 de Silva VA, Senanayake SM, Dias P, et al. From pesticides to medicinal drugs: time series analyses of methods of self-harm in Sri Lanka. Bull World Health Organ 2012;90: 40-46.

5 Gawarammana IB, Ariyananda PL, Palangasinghe C, et al. Emerging epidemic of fatal human self-poisoning with a washing powder in Southern Sri Lanka: a prospective observational study. Clin Toxicol (Phila) 2009;47:407-411.

6 Wijemanne S, Seneviratne HR. Update on contraception - 3. Ceylon Med J 2010;55:60-66.

7 Guidelines for service providers on use of the combined oral contraceptive (COC) pill. National family planning program, Sri Lanka. http://www.familyhealth.gov.lk/web/index.php? option $=$ com_phocadownload $\&$ view $=$ category $\&$ download $=$ 12:26guidelines-for-service-providers-on-the-use-of-cocenglish-\&id=10:family-planning\&Itemid $=68 \&$ lang $=$ ta (accessed 1 Jan 2015).

8 Pearson M, Konradsen F, Gunnell D, et al. A community-based cluster randomised trial of safe storage to reduce pesticide self-poisoning in rural Sri Lanka: study protocol. BMC Public Health 2011;11:879.

9 Marecek J, Senadheera C. 'I drank it to put an end to me': narrating girls' suicide and self-harm in Sri Lanka. Contrib Indian Sociol 2012;46:53-82.

10 Rajapakse T, Griffiths KM, Christensen H. Characteristics of non-fatal self-poisoning in Sri Lanka: a systematic review. BMC Public Health 2013;13:331.

11 De Silva V, Ratnayake A. Increased use of medicinal drugs in self-harm in urban areas in Sri Lanka. Arch Suicide Res 2008; $12: 366-369$.

12 Birth control pill overdose. 16 October 2013. http://www.nlm. nih.gov/medlineplus/ency/article/002599.htm [accessed 1 Jan 2015]. 